\title{
Macrófitas biondicadoras em trecho urbano do Rio Grande - oeste da Bahia
}

\author{
Macrophytes bioindicators in urban stretch of the Grande River - western Bahia
}

\author{
Crisliane Aparecida Pereira dos Santos \\ Universidade do Estado da Bahia - UNEB - Alagoinhas - Bahia - Brasil
}

\section{Resumo}

A eutrofização causada por influência antrópica se caracteriza pelo excesso de nutrientes proveniente de práticas domésticas, agrícolas e industriais em lagos e rios, beneficiando algumas espécies produtoras que crescem em níveis elevados. O presente estudo buscou, através de levantamento bibliográfico, a construção de um panorama da utilização da água na região Oeste da Bahia, e também observou a presença de macrófitas aquáticas bioindicadoras de eutrofização em trecho do Rio Grande. A área analisada correspondeu ao cais da cidade de Barreiras - BA, onde foi encontrada em pequena quantidade, a macrófita do gênero Eichchornia. Não se constatou a presença do processo de eutrofização do Rio Grande, mas a presença da macrófita Eichhornia spp., sugere a existência da poluição hídrica no trecho do Rio Grande analisado. O lançamento de efluentes, ao longo da cidade, reforça a necessidade de monitoramento periódico do rio, adequação de saneamento básico e, principalmente, prevenção da qualidade dos recursos hídricos.

\section{Abstract}

Eutrophication caused by anthropogenic influence is characterized by excess of nutrients in lakes and rivers from domestic, agricultural and industrial practices, benefiting some species that grow at high levels. The present study sought, through a bibliographical survey, the construction of a panorama of the use of water in the Western Bahia, and also observed the presence of aquatic macrophytes bioindicating eutrophication in the stretch of the Grande River. The analyzed area correspond to the pier of Barreiras - BA, where was found a small amount of aquatic macrophyte genre Eichhornia. Not verified the presence of the eutrophication process of the Grande River, but the presence of the macrophyte Eichhornia spp., suggests the existence of water pollution in the section of Rio Grande analyzed. Indicative of effluent discharge along of the city that increases the necessity of surveillance basic sanitation and especially, prevention water resources.

\section{Palavras-chave}

Saneamento Básico.

Eutrofização. Poluição Hídrica.

\section{Keywords}

Basic Sanitation. Eutrophication. Water Polluition. 


\section{Introdução}

A água tem contribuído para o desenvolvimento da urbanização desde os primórdios das civilizações. Sendo um recurso vital e de exacerbado consumo, tem resultado em diversas discussões pelo mundo, sobre o seu uso e as demais consequências da sua escassez para a população humana. Para Setti et al (2001) o crescimento populacional tem apresentado uma relação inversa com os dados quanti-qualitativos da água, o que tem provocado em diversas regiões, problemas de ordem hídrica, como por exemplo, o Estado de São Paulo ou o Polígono das Secas no Nordeste brasileiro.

Diante da problemática do crescimento populacional indiscriminado e da existência de limitações na disponibilidade de recursos hídricos, ou seja, a escassez hídrica, bem como a poluição é que surge, então, a Política Nacional de Recursos Hídricos, instituída pela Lei Federal 9.433, ressaltando a água como um recurso limitado, um bem de domínio público e dotado de valor econômico (BRASIL, 1997). Neste sentido, as constantes pressões e demandas da água pela população crescem em número e em padrões de exigência (MUÑOZ, 2000) quanto ao seu uso sustentável e a sua preservação.

Com o crescimento populacional houve também o aumento da demanda na produção de alimentos (SILVA, 2009; ZANINI, 2009). Ao mesmo tempo, para ampliar a oferta de alimento, em proporções geométricas, a alternativa está no investimento da produção agrícola sob irrigação, tecnologia responsável por um número maior de safras por ano (COSTA e MONDARDO, 2013; SANTOS et al., 2014). Entretanto, simultaneamente a essa oferta de alimentos estão a degradação dos solos, a baixa resposta positiva da produtividade ao uso de fertilizantes e defensivos e a escassez de água, principais entraves à conservação dos recursos naturais (PAZ et al., 2000).

A água utilizada pela agricultura é proveniente tanto pelas chuvas, por meio do processo da infiltração do solo, quanto gerada artificialmente, por meio da irrigação (REBOUÇAS, 2006). Desta forma, um pouco mais de $60 \%$ da produção global de alimentos é atribuída à água da chuva, e quase $40 \%$ à agricultura irrigada (SELBORNE, 2001). Portanto, para minimizar esse impacto ambiental sobre a disponibilidade hídrica é necessário buscar alternativas para aumentar a eficiência na utilização da água da chuva, por meio de manejos do solo que reduzam o escoamento superficial, aumentem a cobertura do solo e consequentemente a taxa de infiltração da água no solo.

A qualidade da água também tem sido colocada à prova a partir da poluição dos lençóis freáticos, por meio da utilização de fertilizantes na agricultura (VESILIND e MORGAN, 2011). Estes contribuem para o aumento da concentração de nutrientes, sobretudo nitrogenados e fosfatados, nos lençóis freáticos ou nos corpos d'água, e podem ocasionar a eutrofização de lagos e reservatórios (RESENDE, 2002), além de riachos e rios.

Outra fonte de contaminação são os depósitos de lixo urbanos que pela lixiviação do chorume, sobretudo nos períodos chuvosos, entram em contato com a água dos rios e lençóis freáticos (BARRETO et al., 2013).

O tipo de uso e ocupação do solo, a disposição inadequada de resíduos sólidos e o lançamento indevido dos resíduos domésticos e industriais (JESUS e SOUZA, 2013) vem intensificando o processo de poluição e degradação dos recursos hídricos no ambiente urbano. Isto porque os efluentes não tratados, como lixo e esgotos domésticos, tem seu destino final 
em rios, lagos e oceanos, contribuindo, consequentemente para o processo da eutrofização dos recursos hídricos (GALVÃO JÚNIOR e PAGANINI, 2009).

Portanto, como consequência das atividades antrópicas a poluição dos corpos hídricos tem provocado alterações ou perturbações das comunidades bióticas, além do aumento da degradação da qualidade das águas e estudos utilizando macrófitas aquáticas como bioindicadoras de qualidade de água tornam-se cada vez mais essenciais, haja a vista a sua escassez, especialmente em ambientes lóticos (HEGEL e MELO, 2016).

O presente estudo buscou, através de levantamentos bibliográficos, dados secundários, a construção de um panorama da utilização da água na região Oeste da Bahia, e também observar, via dado primário, a presença de macrófitas aquáticas bioindicadoras de eutrofização em trecho do Rio Grande.

\section{Eutrofização como degradação dos recursos hídricos}

A eutrofização consiste no processo de enriquecimento de corpos hídricos por nutrientes, principalmente fósforo e nitrogênio, provenientes dos efluentes sem tratamento (VON SPERLING, 1996; ZANINI, 2009, BARRETO et al., 2013). As altas concentrações de nitratos e fosfatos podem causar um supercrescimento de algas e plantas aquáticas na água para níveis com redução significativa dos níveis de oxigênio na água (PELCZAR JUNIOR et al.,1997). Além de poder levar à alteração no sabor, no odor, na turbidez e na cor da água, à redução do oxigênio dissolvido, provocando morte de espécies sensíveis (BLINI, 2015).

Devido a esses processos de degradação ambiental a presença de organismos bioindicadores é de extrema importância, a sua ausência ou presença podem indicar características do meio como a concentração elevada de nitrogênio e fósforo (VON SPERLING, 1996; PELCZAR JUNIOR et al.,1997; VESILIND e MORGAN, 2011). Isto em função de serem organismos sensíveis a diferentes substâncias tóxicas, tais como metais pesados, efluentes, entre outros, pré-requisito indispensável a um bioindicador de poluição ambiental (PEIXOTO et al., 2005).

Além do crescimento de algas, o processo de eutrofização também possibilita o adensamento de plantas aquáticas flutuantes (NARDIDI e NOGUEIRA, 2008; BLINI, 2015), fazendo com que a falta de luz, representada pela coloração turva da água, provoque uma grande redução dos níveis de oxigênios dissolvidos e o aumento da morte de espécies vegetais e animais, ou seja, um grande impacto negativo à qualidade do corpo hídrico.

As macrófitas aquáticas, componentes naturais de ecossistemas, são plantas visíveis a olho nu fotossinteticamente ativas, podendo estar permanentemente, total ou parcialmente submersas, em água doce ou salobra, por períodos contínuos (diversos meses, todos os anos), ou flutuantes (IRGANG e GASTAL JUNIOR, 1996).

Um fato que tem dado visibilidade a estes biondicadores é a alteração na dinâmica de cursos d'agua, como reservatórios e lançamento de efluentes que aumentam a população dessas macrófitas. Portanto, plantas como aguapés (Eichhornia sp.), orelha-de-onça (Salvinia $s p$.$) e alface-d'água (Pistia sp.) podem indicar o estado de conservação de rios e lagos, sendo$ também influenciada pelas características físicas do corpo hídrico, velocidade de escoamento e tempo de residências (AZEVEDO NETTO, 1988).

A floração de algas e cianobactérias em ambientes de alta atividade humana, sejam urbana ou agrícola, estão intrínsecas ao lançamento de nutrientes em corpos hídricos, 
ocasionados por lançamentos de esgotos, fertilizantes, erosão e resíduos industriais, que isoladamente ou cumulativamente aceleram a produtividade primária e o crescimento das algas, além de um desequilíbrio ecológico das espécies aquáticas (NARDIDI e NOGUEIRA, 2008).

As macrófitas aquáticas para Palma-Silva et al. (2012) apresentam aspectos positivos (servindo como produtores primários, abrigo para invertebrados e vertebrados, como fonte de alimento a outros organismos e sobretudo, na absorção de nutrientes do meio e incorporação em sua biomassa) e negativos (pela contribuição para o processo de eutrofização, devido encontrarem nos ambientes eutrofizados, com alta concentração de matéria orgânica, condições favoráveis ao seu crescimento descontrolado), levando em consideração componentes de ecossistemas naturais e artificiais.

Dentro dos aspectos positivos, a habilidade de acelerar a ciclagem e acumular os nutrientes é tida como a principal característica das macrófitas aquáticas (ANGELINI et al., 2008; BARRETO et al., 2013), sobretudo para a sua capacidade de acúmulo de nitrogênio e fósforo (PALMA-SILVA et al., 2012), bem como interfere na sedimentação, na velocidade do fluxo de água, enfim nas características físicas e químicas das águas de rios e riachos (HEGEL e MELO, 2016).

E em águas eutrofizadas as macrófitas mais comumente encontradas no Brasil são as Eichhornia, Pistia, Potalogeton, Ceratopbyllum, Mycrophyllum (AZEVEDO NETTO, 1988). A Eichhornia crassipes, por exemplo, apresenta alta capacidade de absorção de nutrientes, durante o seu crescimento, em ambientes eutrofizados, o que justifica o seu uso, via fitorredemiação, em pequenos corpos hídricos eutrofizados (PALMA-SILVA et al., 2012).

Por outro lado, como aspecto negativo das macrófitas aquáticas, pode-se citar como exemplo no Brasil, o caso registrado do Lago Paranoá em Brasília, 1982, em que foi necessária a remoção manual e com dragas da macrófitas Eichhornia crassipes (ANGELINI et al., 2008). Naquele momento, a mortandade de peixes pôde ser explicada pela depleção do oxigênio existente no lago, consequência do excesso de nutrientes e aumento da população dessas macrófitas bioindicadoras.

Embora as macrófitas aquáticas apresentem mais benefícios que potencialidades negativas, deve-se levar em conta que para o sucesso de seu uso, aspectos como, a espécie utilizada, idade da planta, parte da planta, período do ano, forma biológica da macrófita (se fixa ou flutuante), dentre outros devem ser adotados cuidadosamente (AZEVEDO NETTO, 1988; PALMA-SILVA et al., 2012; HEGEL e MELO, 2016).

O Oeste da Bahia possui 24 municípios, detentores da vegetação típica do Cerrado, com solos originalmente de baixa fertilidade química, mas que se transformaram num grande potencial econômico devido ao avanço tecnológico da agricultura na região, a partir do final da década de 1970 com a chegada dos imigrantes sulistas (COSTA e MONDARDO, 2013).

De acordo Moreira e Silva (2010) a bacia do Rio Grande, situada no médio São Francisco possui grande importância no cenário econômico e ambiental, tanto no contexto estadual quanto nacional, visto que essa bacia apresenta grande disponibilidade hídrica e, além disso, seus rios apresentam, de modo geral, ótimas condições de qualidade de suas águas, segundo as análises de 72 parâmetros realizadas em 10 pontos ao longo do rio, durante o ano de 2007, pelo INGÁ (Instituto de Gestão das Águas e do Clima).

Entretanto, o crescimento econômico da região não foi acompanhado pelo desenvolvimento social e sem infraestrutura adequada de saneamento básico para a demanda 
do rápido crescimento da cidade, os arredores do Rio Grande foram sendo ocupados e como consequência houve o aumento de resíduos, desprovidos de qualquer tipo de tratamento, despejados diretamente no rio (EMBASA, 2010).

Trabalhos com macrófitas aquáticas no Brasil com o intuito de monitorar qualidade das águas são muito escassos (PALMA-SILVA et al., 2012; HEGEL e MELO, 2016), sobretudo no Nordeste brasileiro e consequentemente no Oeste da Bahia. Assim, este trabalho estuda o potencial uso das macrófitas aquáticas como biondicadoras de qualidade das águas do Rio Grande, Oeste da Bahia, em trecho urbano de Barreiras - BA.

\section{Material e métodos}

\section{Área de estudo}

A área de estudo compreende o município de Barreiras, com localização no Oeste da Bahia, situada, a $12^{\circ} 08^{\prime} 48^{\prime \prime}$ de latitude Sul e $44^{\circ} 50^{\prime} 58^{\prime \prime}$ de longitude Oeste, dista a $904 \mathrm{~km}$ de Salvador e $622 \mathrm{~km}$ de Brasília, seguido de uma área territorial municipal de mais de $7 \mathrm{mil} \mathrm{km}{ }^{2}$ (IBGE, 2010).

O município de Barreiras encontra-se localizado na bacia hidrográfica do Rio Grande, afluente da margem esquerda da bacia do rio São Francisco (Figura 1) e com uma população estimada de 150.896 habitantes para 2013 (IBGE, 2010).

O Rio Grande nasce entre a divisa dos Estados de Goiás e Bahia e desagua no Rio São Francisco, município de Barra, após 502 km de percurso. Assim, estão incluídos nos seus limites territoriais os municípios de Angical, Baianópolis, Barra, Barreiras, Buritirama, Catolândia, Cotegipe, Cristópolis, Formosa do Rio Preto, Luís Eduardo Magalhães, Mansidão, Muquém do São Francisco, Riachão das Neves, Santa Rita de Cássia, São Desidério, Tabocas do Brejo Velho, e Wanderley (MOREIRA e SILVA, 2010), sendo o município de Barreiras o único limite a ser estudado conforme demonstra a Figura 1.

(a)

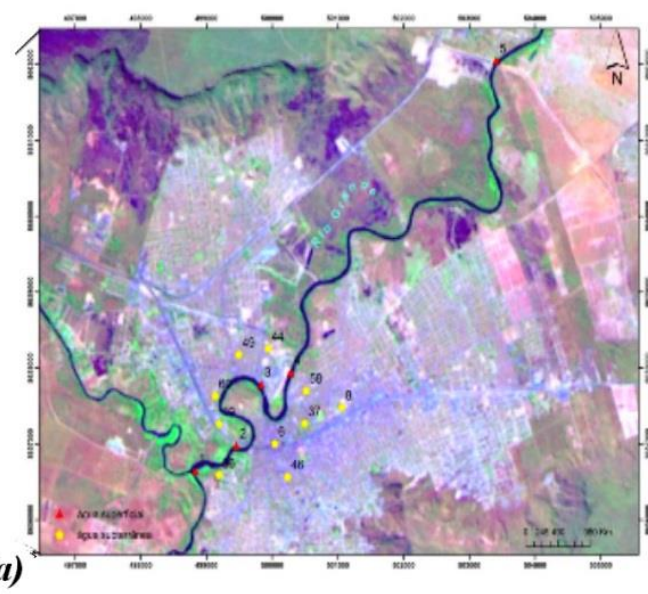

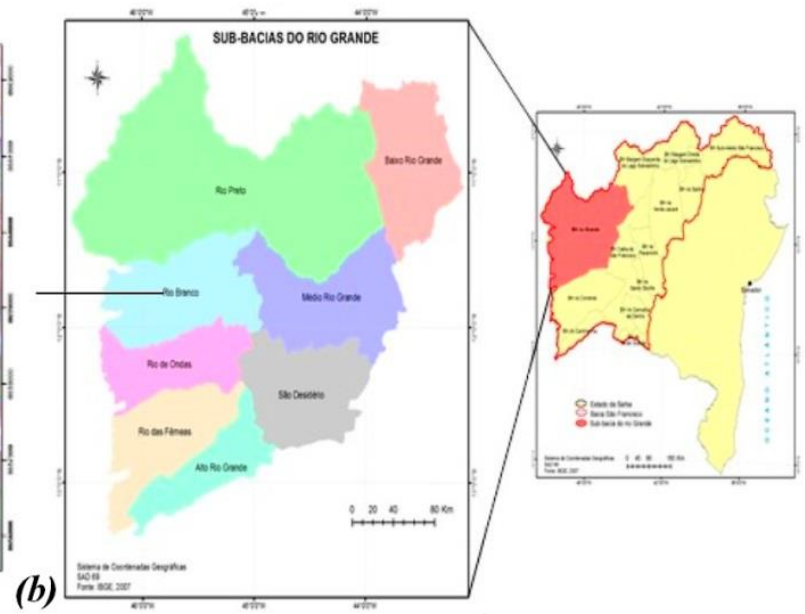

O local de coleta denominado Cais e Porto, outrora tido como uma via de navegação, ou seja, como um ponto de embarque e desembarque de mercadorias que abastecia o município de Barreiras, durante o período de 1891 - 1964 (PDU, 2004), está localizado na margem do Rio Grande, no perímetro urbano central de Barreiras, com lançamento contínuo de efluentes e devido a falta serviços de esgotamento sanitário, polui a água, impacta as espécies aquáticas existentes, além de geração de odores desagradáveis, o que inviabiliza o uso dessas águas para fins de lazer e balneabilidade. 


\section{Metodologia aplicada}

Primeiramente realizou-se um levantamento de dados bibliográficos, a partir da consulta de materiais diversos (artigos, dissertação, dentre outros), sobre o uso das macrófitas em águas eutrofizadas, bem como sobre a condição sanitária dos corpos hídricos do município de Barreiras - BA.

Em seguida, as macrófitas foram coletadas, no período seco, e posteriormente identificadas em laboratório de Botânica da Universidade do Estado da Bahia (UNEB/Campus IX), segundo Kissmann (1997). Para essa etapa as macrófitas foram previamente prensadas e desidratadas a uma temperatura de $60^{\circ} \mathrm{C}$ por um período de $72 \mathrm{~h}$.

\section{Resultados e discussões}

A cidade de Barreiras se desenvolveu rapidamente a partir da década de 1980, período, que retrata a ascensão do agronegócio, a chegada das agroindústrias e o crescimento populacional (COSTA e MONDARDO, 2013).

Entretanto, como consequências, vieram os problemas socioambientais, como por exemplo, a inexistência de infraestrutura local, a falta de saneamento básico, o aumento do uso de fertilizantes químicos, todos afetando, consideravelmente, o solo, a vegetação e, principalmente, os recursos hídricos (SANTOS et al., 2014). O lançamento de esgoto não tratado e a contaminação por adubos e fertilizantes, em rios e lagos, são a principal fonte para o processo de eutrofização em corpos hídricos na região de estudo.

Nesse contexto, o município de Barreiras, localizado no Oeste da Bahia, sofre atualmente com grandes preocupações socioambientais, onde se discutem a utilização de suas águas e a sua degradação. E diante disso, a expansão acelerada da urbanização associada à intensidade do uso e ocupação dos solos, tornaram-se agravantes às mudanças ambientais de rios e córregos, como por exemplo, alteração da população microbiana decompositora da matéria orgânica em acúmulo (PELCZAR JUNIOR et al., 1997).

A partir dessas alterações aos corpos hídricos, iniciada com a expansão da população a partir da primeira metade da década de 1980, que passou a ocupar de forma desordenada as margens do Rio grande, inicia-se a preocupação com esses recursos e a sua gestão, merecendo atenção das autoridades locais, do Estado e da União, como também, de sua população, por meio da formação da conscientização social (COSTA e MONDARDO, 2013; SANTOS et al., 2014).

Das diversas problemáticas do município, atualmente o saneamento básico é o mais alarmante. Em 2010, a abrangência do sistema de esgotamento sanitário existente na cidade atingia apenas $10 \%$ da população urbana e inexistente para a população rural. Já em 2016, com a expansão deste sistema a cobertura passou a alcançar $44 \%$ da população urbana (MURAL DO OESTE, 2016).

$\mathrm{Na}$ cidade de Barreiras a rede coletora de esgoto foi projetada e implantada em diferentes épocas e não contempla todo o município, sendo o acesso aos serviços de saneamento básico é condição fundamental para a sobrevivência e dignidade humana. E a sua ausência traz consequências graves em termos de saúde pública, meio ambiente e cidadania (GALVÃO JÚNIOR e PAGANINI, 2009). Assim, a falta de ligações, seja ela por falta de redes nas vias ou devido a problemas de cotas resulta no lançamento de esgotos in natura em todos os 
córregos da malha urbana, ocasionando proliferação de doenças e degradação ambiental (EMBASA, 2010).

Um dos corpos receptores desses resíduos é o Rio Grande, que recebe as contribuições dos esgotos, ao mesmo tempo em que também recebe aportes de fertilizantes químicos por meio de ocupações agropecuárias localizadas tanto ao seu entorno quanto em áreas distantes da zona urbana (EMBASA, 2010). E esse aporte de esgotos tem provocado ao longo do tempo alterações nas propriedades físico-químicas e biológicas, com redução da qualidade da água e aumento da proliferação de macrófitas, resultado do incremento de nutrientes a partir dessas fontes supracitadas.

O INEMA (Instituto do Meio Ambiente e Recursos Hídricos), em sua primeira campanha de monitoramento da qualidade de rios em 2011, constatou que o Rio Grande está em boas condições, considerando fatores químicos, físicos e biológicos para a classificação do Índice de Qualidade das Águas (IQA). A coleta das amostras foi feita em dois pontos distintos: sob a ponte no centro do município de Barreiras $\left(12^{\circ} 08^{\prime} 54,4^{\prime \prime} \mathrm{S}, 45^{\circ} 00^{\prime} 11,9^{\prime \prime} \mathrm{W}\right.$ ) e no ponto à jusante da zona urbana da cidade, local conhecido como porto de lavagem de brita (12 $07^{\prime} 11,6^{\prime \prime} \mathrm{S}$, $\left.44^{\circ} 58^{\prime} 04,6^{\prime \prime} \mathrm{W}\right)$.

Comparando os dados da coleta, o índice da qualidade da água foi inferior no ponto à jusante, o que denota a interferência urbana na qualidade do rio. A observação se deteve às margens do Rio Grande, começando a partir da ponte Ciro Pedrosa e seguindo o curso do rio até o fim da malha urbana em seu entorno. A interferência urbana foi facilmente percebida pelo lançamento direto de esgoto, supostamente não tratado, em mais de um ponto ao longo do cais da cidade (Figura 2), contrariando o Art.3ㅇ da resolução Conama 430/2011, que determina o lançamento de efluentes somente após o devido tratamento. Esta área se caracteriza, dentre outros aspectos, pelo mau cheiro e a poluição das margens do rio, além do maior comprometimento de aspectos visuais, como a exemplo, a elevação da turbidez.

(a)

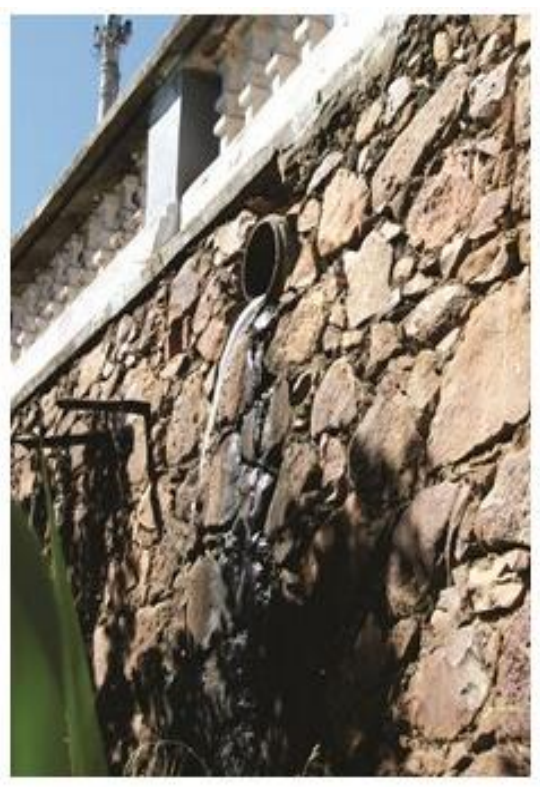

(b)

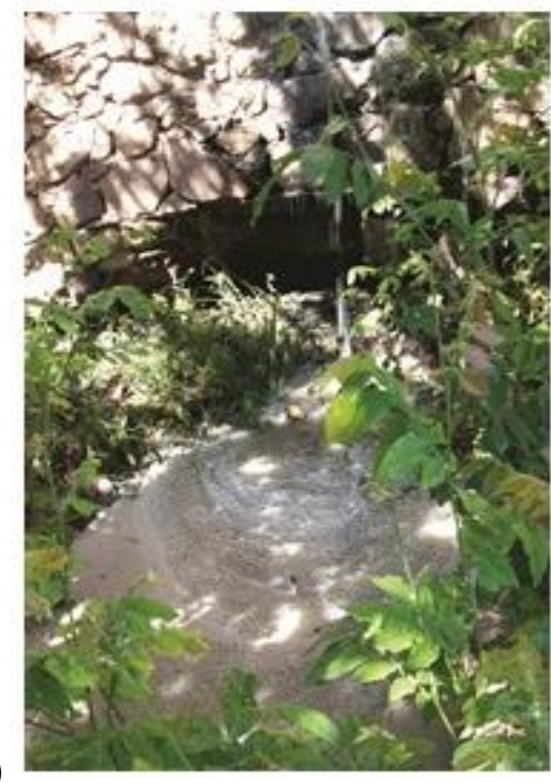

Os resultados desse trabalho mostraram que além da degradação desse recurso hídrico associada à malha urbana, é importante salientar, que este também causa influência na qualidade de vida da população, isto porque além desta fonte pontual de poluição, o mesmo corpo hídrico recebe grandes cargas de poluição a montante, como exemplo, da agricultura. 
Situação agravada, neste mesmo trecho do rio, por uma intensa retirada da mata ciliar com vulnerabilidade a futuros assoreamentos.

Ainda foi encontrado em pequenas quantidades, no trecho analisado, a presença de macrófitas aquáticas flutuantes do gênero Eichhornia spp. (Figura 3). Essa macrófita tem a capacidade de acumular substâncias tóxicas e grande quantidade de nutrientes (PALMA-SILVA et al., 2012). A sua presença pode indicar excesso de nutrientes no ambiente aquático pelo lançamento de esgoto sem tratamento, no Rio Grande, justamente por ser um organismo bioindicador. Isso também pode indicar que na área de estudo há o lançamento de efluentes domésticos, uma vez que a macrófita foi encontrada somente após a área urbana. Os dados ainda denotam a existência de um crescimento contínuo da população de macrófitas pelo lançamento constante do esgoto in natura no rio.
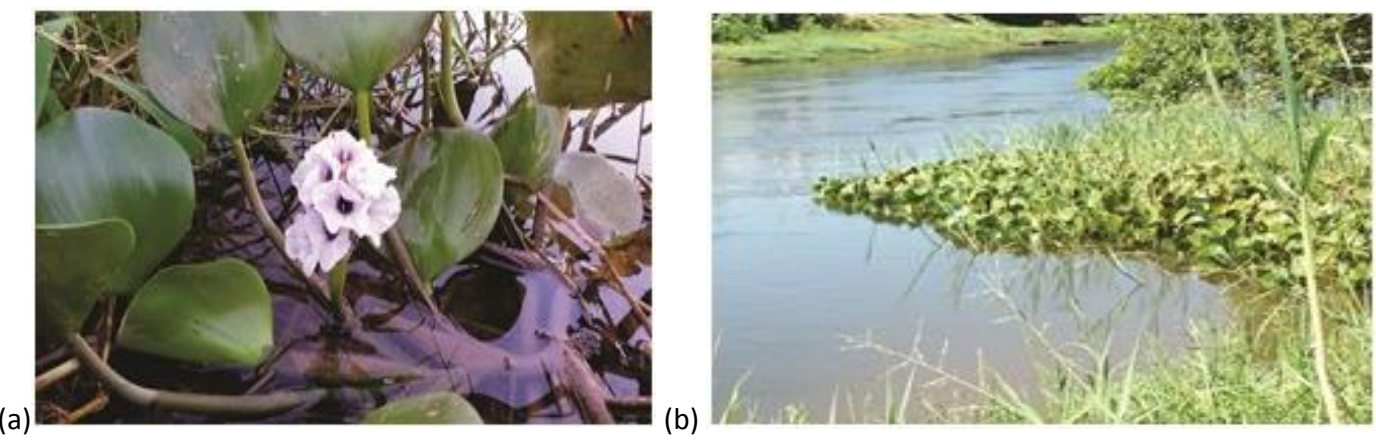

Os dados também corroboram com aqueles defendidos por Palma-Silva et al. (2012), onde a Eichhornia spp. é uma macrófita flutuante que participa do controle da poluição, mediante a sua capacidade de absorção dos nutrientes provenientes do lançamento dos efluentes. Também foi perceptível que esta espécie de macrófita é considerada daninha ou invasora, em razão de se infestar espontaneamente em áreas com alterações antrópicas (VARGAS e ROMAN, 2008).

A eutrofização também pode vir a ocorrer em rios, embora menos frequente em virtude das condições ambientais serem melhores, como turbidez e velocidades elevadas e, portanto, mais desfavoráveis para o crescimento de algas e outras plantas (VON SPERLING, 1996). Assim, devido às características do Rio Grande, que tem alto poder de depuração, não se constatou a presença do processo de eutrofização, pois é continuamente lavado pelas águas, funcionando como um "reator de fluxo a pistão", cujo pistão de água se move a jusante, na velocidade do fluxo, e as reações que ocorrem são analisadas, tais como o nível do oxigênio dissolvido (VESILIND e MORGAN, 2011), característica de um ambiente lótico, muito embora já se possa supor a existência de uma poluição hídrica justificada pela presença da macrófita Eichhornia spp.

Segundo Hegel e Melo (2016) o grande desenvolvimento vegetativo de uma macrófita aquática pode estar associado ao aumento da eutrofização da água, o que reforça a hipótese de alteração da qualidade da água. Assim, caso se perceba, ao longo do tempo o incremento da população dessas macrófitas no trecho analisado, significa que o mesmo possa estar tendo uma drástica redução da qualidade de suas águas, acompanhado de possíveis indícios de eutrofização, embora em ambientes lóticos esta não seja uma característica tão comum. 
A abundância e produtividade dessas macrófitas podem ser explicadas pelas altas concentrações de N e P na água (VARGAS e ROMAN, 2008; HEGEL e MELO, 2016), assim como a maior ocorrência de espécies flutuantes vistos na Figura 3.

É interessante destacar que ao mesmo tempo em que ela pode se comportar positivamente no controle da poluição, a sua abundância também pode reduzir a superfície de troca de oxigênio dissolvido na interface água - atmosfera. E isso é um fator a ser considerado, haja vista que a população dessas macrófitas flutuantes na água mantém as concentrações do oxigênio dissolvido abaixo dos valores limites para a ictiofauna (MARTINS e PITELLI, 2005).

Conclui-se que devido a presença de macrófitas aquáticas (Eichhornia spp.), que recebe grandes aportes de efluentes e de outras interferências antrópicas, no trecho analisado do Rio Grande, que a qualidade de suas águas apresentam alterações devido, sobretudo ao acúmulo de nutrientes em grandes quantidades.

\section{Conclusões}

Os dados apresentados sugerem que a modernização agropecuária e o crescimento populacional possuem uma relação negativa com a manutenção quali-quantitativa dos corpos hídricos na região de estudo, pelo lançamento indevido de esgoto in natura na malha urbana. Entretanto, não se constatou a presença do processo de eutrofização do Rio Grande, provavelmente em função das características físico-químicas do rio, assim como pelo baixo adensamento da população de Eichhornia spp.

Da mesma forma, a presença da macrófita Eichhornia spp., sugere a existência da poluição hídrica no trecho do Rio Grande analisado, provavelmente pelo aumento da deposição de matéria orgânica na água.

Assim, torna-se necessário o monitoramento periódico do Rio Grande, a fim de se observar possíveis alterações nos parâmetros físico-químicos e biológicos, especialmente quanto as concentrações de nitrato e fosfato, bem como a avaliação das populações de macrófitas bioindicadoras. E os resultados do estudo reforçam a necessidade de fiscalização quanto ao lançamento de efluentes sem tratamento no Rio Grande, bem como da adequação do saneamento básico municipal.

\section{Agradecimentos}

Agradeço a colaboração científica dos alunos egressos, do curso de Licenciatura em Ciências Biológicas da UNEB/Campus IX, Danilo Rocha de Melo, Bruna Maiara Vieira Carvalho e Mônica dos Santos de Mello.

\section{Referências}

1. AZEVEDO NETTO, J. M. Novos conceitos sobre eutrofização. Revista DAE, v.48, n.151, p.22-28, 1988.

2. ANGELINI, R.; BINI, L. M.; STARLING, F. Efeitos de diferentes intervenções no processo de eutrofização do lago Paranoá (Brasília-DF). Oecologia Brasiliensis, v.12, n.3, p.564-571, 2008 
3. BARRETO, L. V.; BARROS, F. M.; BONOMO, P. R.; FElIZARDO, A.; AMORIM, J. S. Eutrofização em rios brasileiros. Enciclopédia Biosfera, Centro Científico Conhecer, v.9, n.16, p.2165-2179, 2013.

4. BLINI, R. C. B. Eficiência dos bioindicadores para avaliação na qualidade das águas superficiais da Lagoa Maior urbana de Três Lagoas/MS. 2015. 102 p. Dissertação (Programa de pós-graduação em Geografia - Mestrado) - Universidade Federal de Mato Grosso do Sul - UFMS, 2015.

5. BRASIL. Lei $\mathbf{9 . 4 3 3 / 1 9 9 7 , ~ I n s t i t u i ~ a ~ P o l i ́ t i c a ~ N a c i o n a l ~ d e ~ R e c u r s o s ~ H i ́ d r i c o s , ~ p r o m u l g a d a ~ e m ~}$ de 8 de janeiro de 1997. Brasília: DOU, 1997.

6. COSTA, D. H.; MONDARDO, M. L. A modernização da agricultura no oeste baiano: migração sulista e novas territorialidades. Revista Geonorte, v.7, n.1, p.1371-1385, 2013.

7. EMBASA - Empresa Baiana de Águas e Saneamento SA. Plano Setorial de Abastecimento de Água e Esgotamento Sanitário de Barreiras. 2010. Disponível em: <http://barreiras.ba.gov.br/pdf/rel_pssb_barreiras.pdf>. Acesso em 17 de Abr. 2016.

8. GALVÃO JUNIOR, A. C.; PAGANINI, W. S. Aspectos conceituais da regulação dos serviços de água e esgoto no Brasil. Engenharia Sanitária e Ambiental, v.14, n.1, p.79-88, 2009.

9. HEGEL, C. G. Z.; MELO, E. F. R. Q. Macrófitas aquáticas como bioindicadoras da qualidade da água dos arroios RPPN Maragato. Revista em Agronegócio e Meio Ambiente, v.9, n.3, p.673-693, 2016.

10. IBGE - Instituto Brasileiro de Geografia e Estatística. Cidades 2010. Disponível em < http://cidades.ibge.gov.br/xtras/perfil.php?codmun=290320>. Acesso em 28 de Abr. 2016.

11. IRGANG, B. E.; GASTAL JÚNIOR, C. S. Macrófitas aquáticas da planície costeira do RS. 1. ed., UFRGS: Porto Alegre, 1996. 290p.

12. KISSMANN, K. G. Plantas infestantes e nocivas: tomo I: plantas inferiores, monocotiledôneas. 2. ed. São Paulo: BASF, 1997. v.1. 825p.

13. MARTINS, A. T.; PITELLI, R. A. Efeitos do manejo de Eichchornia crassipes sobre a qualidade da água em condições de Mesocosmos. Planta Daninha, v.23, n.2, p.233-242, 2005.

14. MOREIRA, M. C.; SILVA, D. D. (2010). Atlas hidrológico da bacia hidrográfica do rio Gran de. Barreiras, BA: Editora Gazeta Santa Cruz. 2010. 41p.

15. MUÑOZ, H. R. Interfaces da gestão de recursos hídricos: desafios da Lei de Águas de 1997. 2. ed. Brasília: Secretaria de Recursos Hídricos, 2000. 421p.

16. MURAL DO OESTE - Notícias do Oeste Baiano. Rede de esgoto alcança $\mathbf{3 1}$ bairros de Barreiras. Disponível em http://www.muraldooeste.com/2016/09/rede-de-esgotoalcanca-31-bairros-de.html. Acesso em 16 de Out. 2016.

17. NARDINI, M. J.; NOGUERA, I.S. O Processo Antrópico de um Lago Artificial e o Desenvolvimento de Eutrofização e Florações de Algas em Goiânia. Estudos, v.35, n.1, p.23-52, 2008.

18. PALMA-SILVA, C; ALBERTONI, E. F.; TRINDADE, C. R. T.; FURLANETTO, L. M.; COSTA, M. C. Uso de Eichhornia Crassipes (Mart.) Solms para Fitorremediação de Ambientes Eutrofizados Subtropicais no Sul do Brasil. Perspectiva, v.36, n.133, p.73-81, 2012. 
19. PAZ, V. P. S.; TEODORO, R. E. F.; MENDONÇA, F. C. Recursos Hídricos, Agricultura Irrigada e Meio Ambiente. Revista Brasileira de Engenharia Agrícola e Ambiental, v.14, n.3, p.465-473, 2000.

20. PDU - Plano Diretor Urbano. Síntese do plano diretor urbano. Prefeitura Municipal de Barreiras, Bahia. 2004. 141p. Disponível em < http://barreiras.ba.gov.br/wpcontent/uploads/2015/11/PDDU-RT-4-Relat\%C3\%B3rio-do-S\%C3\%ADntese-doPDU2.pdf >. Acesso em 08 de Ago. 2017.

21. PEIXOTO, P. H. P.; PIMENTA, D. S.; ANTUNES, F. Efeitos do flúor em folhas de plantas aquáticas de Salvinia auriculata. Pesquisa Agropecuária Brasileira, v.40, n.8, p.727-734, 2005.

22. PELCZAR JUNIOR, M. J.; CHAN, E. C. S.; KRIEG, N. R. Microbiologia: conceitos e aplicações. v.1, 2. ed. São Paulo: Pearson Makron Books, 1997.

23. REBOUÇAS, A. C. Água doce no mundo e no Brasil. In: REBOUÇAS, A. C.; BRAGA, B.; TUNDISI, J. G. (Org.). Águas doces no Brasil: capital ecológico, uso e conservação. 2. ed. São Paulo: Escrituras, 2006. 703p.

24. RESENDE, Á. V. Agricultura e qualidade da água: contaminação da água por nitrato. Planaltina: Embrapa Cerrados, n. 57, 2002. 29p.

25. SANTOS, C. A. P.; LEITE, O. D.; VIEIRA, A. D. M. Diagnóstico preliminar de parâmetros físico-químicos das águas superficiais e subterrâneas do município de Barreiras-BA antes da ampliação do saneamento básico. Revista Brasileira de Ciências Ambientais, n.32, p.12-23, 2014.

26. SELBORNE, L. A Ética do Uso da Água Doce: um levantamento. Brasília: UNESCO, 2001. 80p.

27. SETTI, A. A.; LIMA, J. E. F. W.; CHAVES, A. G. M.; PEREIRA, I. C. Introdução ao Gerenciamento de Recursos Hídricos. 2. ed. Brasília: Agência Nacional de Energia Elétrica, Superintendência de Estudos e Informações Hidrológicas, 2001. 328p.

28. SILVA, A. I. Recursos Hídricos: Gestão e Impactos Ambientais. 2009. 45p. Monografia (Programa de pós-graduação em Gestão Ambiental - Especialização) - Universidade Cândido Mendes - UCAM, 2009.

29. VARGAS, L.; ROMAN, E. S. Manual de manejo e controle de plantas daninhas. 2. ed. Passo Fundo: Embrapa Trigo, 2008. 779p.

30. VESILIND, P. A.; MORGAN, S. M. Introdução à Engenharia Ambiental. 2. ed. São Paulo: Cengage Learning, 2011. 438p.

31. VON SPERLING, M. Introdução à qualidade das águas e ao tratamento de esgotos. 2 . ed. Belo Horizonte: Departamento de Engenharia sanitária e Ambiental, Universidade Federal de Minas Gerais, 1996. 243p.

32. ZANINI, H. L. H. T. Caracterização limnológica e microbiológica do córrego rico que abastece Jaboticabal (SP). 2009. 75p. Tese (Programa de pós-graduação em Microbiologia Agropecuária - Doutorado) - Universidade Estadual Paulista - UNESP, 2009. 